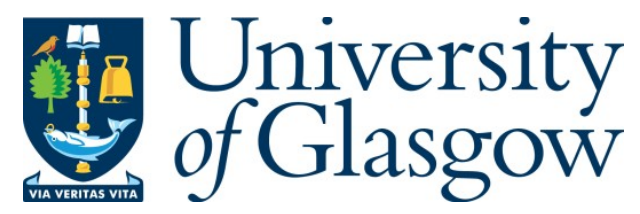

Narayan, A. K., Northcott, D. and Parker, L. D. (2017) Managing the accountability-autonomy tensions in university research commercialisation. Financial Accountability and Management, 33(4), pp. 335-355.

(doi:10.1111/faam.12127).

There may be differences between this version and the published version. You are advised to consult the publisher's version if you wish to cite from it.

This is the peer reviewed version of the following article:

Narayan, A. K., Northcott, D. and Parker, L. D. (2017) Managing the accountability-autonomy tensions in university research commercialisation. Financial Accountability and Management, 33(4), pp. 335-355, which has been published in final form at 10.1111/faam.12127. This article may be used for noncommercial purposes in accordance with Wiley Terms and Conditions for SelfArchiving.

http://eprints.gla.ac.uk/128293/

Deposited on: 22 August 2017

Enlighten - Research publications by members of the University of Glasgow http://eprints.gla.ac.uk 


\section{Managing the Accountability-Autonomy Tensions in University Research Commercialisation}

Authors:

Anil K. Narayan, Senior Lecturer, AUT Business School, The Auckland University of Technology, New Zealand.

Deryl Northcott, Professor of Management Accounting, AUT Business School, The Auckland University of Technology, New Zealand.

Lee D. Parker, Professor of Accounting, RMIT University, Melbourne, Australia and Visiting Professor, University of Glasgow, UK.

Correspondence address:

Anil K Narayan, AUT Business School, The Auckland University of Technology, Private Bag 92006, Auckland 1142, New Zealand.

E-mail address: anil.narayan@ aut.ac.nz

Phone: +64 99219999 Ext 5121

Running title: Managing Accountability-Autonomy Tensions 


\title{
Managing the Accountability-Autonomy Tensions in University Research Commercialisation
}

\begin{abstract}
This paper investigates organisational responses to emerging concerns about how accountability-autonomy tensions can be managed within the context of university research commercialisation. The findings suggest that changed expectations of university research practices, which result from the introduction of a commercialisation logic, can be managed via the homogenisation of research goals and strategies. The successful management of accountability-autonomy tensions also depends on utilising the various structures and cultural contexts that can be facilitated by decoupling and bridging strategies. Further, while adopting symbolic systems may enhance legitimacy, failure to implement material practices and provide the appropriate cultural context to manage conflicting relationships may put university commercialisation ambitions at risk.
\end{abstract}

Keywords: accountability, autonomy, commercialisation, research, universities. 


\section{Managing the Accountability-Autonomy Tensions in University Research Commercialisation}

\section{INTRODUCTION}

As research and its commercialisation have increasingly impacted on economies and societies, demands for accountability and relevance in university research have grown. In addition to teaching and research, universities have a new mission to achieve knowledge transfer and the commercialisation of research results (Nelles and Vorley, 2010). Research commercialisation is defined as "the transformation of basic knowledge into marketable new products and services" thereby contributing to improved economic and social outcomes (Laperche, 2002, p. 150). It reflects the logic of market forces, with a shift in the focus of academic research towards revenue-seeking (Lapsley and Miller, 2004).

The changed commercial expectations of university research give rise to accountabilityautonomy tensions that can be divisive and undermine the academic values of universities. Today, universities operate in an environment where economic and political interests intrude on their internal autonomy, research strategies are increasingly market-oriented, and the focus is moving towards applied, commercialised research and the management of intellectual property (Gulbrandsen and Smeby, 2005; Salmi, 2007).

The aim of this paper is to address an unexplored question, i.e. how do universities of varying histories and orientations address the management of underlying tensions between researcher autonomy and accountability that arise from the increasing trend towards research commercialisation? While extant studies point to the contextual drivers, the role of various stakeholders, the impacts on researchers and the outcomes for universities, little research has been conducted into the dynamics and challenges of managing this process. In particular, there has been no consideration of how universities' differing backgrounds shape their strategies for managing accountability-autonomy tensions.

Why is this issue important? The challenges of research commercialisation have shifted the research management focus from supporting autonomous individual researchers to fostering, managing and evaluating research teams that can produce commercialiseable knowledge. However, this has led to tensions between university managers and researchers as the latter challenge perceived intrusions into their autonomy and growing demands for research entrepreneurship (Salmi, 2007). This raises questions concerning what strategies universities can use to diffuse these tensions, and whether the same strategies can work for universities at differing stages of their research and commercialisation development. 
This study demonstrates that managing tensions requires accommodating commercialisation within the university structure in a homogeneous manner so that it does not undermine the scholarly research culture and values of academic freedom and autonomy that have shaped research within universities (Deem, 2004). It will also reveal the complexities of strategising and managing the commercialisation process, particularly regarding the crucial task of dealing with competing external and internal logics. Structures and processes of bridging, buffering and decoupling will all be shown to play potential roles in managing accountability-autonomy tensions.

Using case studies of two New Zealand universities engaged in research commercialisation, we investigate the related accountability-autonomy tensions and propose ways to manage them. The next section reviews relevant literature on the challenges of research commercialisation to explain the underlying tensions between researcher autonomy and accountability. We then describe our theoretical framework and research method and present our findings and discussion. Finally, we develop conclusions and implications for future research.

\section{THE CHALLENGES OF UNIVERSITY RESEARCH COMMERCIALISATION}

With diminishing government funding, universities have been conditioned towards an increasing degree of self-financing (Parker, 2013). To this end, governments have prompted universities to reshape their research orientations and structures by partnering with private sector corporations, seeking grants from external funding bodies, patenting discoveries, providing research-based corporate advisory services and of course commercialising research outputs, perhaps by creating spinoff companies (Parker, 2012; Soley, 1995). Extracting financial revenues for and from research has become a new performance benchmark for assessing researcher success (Parker and Guthrie, 2005; Washburn, 2005). Hence, university research projects and teams have developed a greater emphasis on serving the private rather than public interest, as commercial revenues are assiduously pursued and the financial interests of universities and their private sector partners dominate research strategies (Washburn, 2005). University researchers in turn become reconfigured as research entrepreneurs (Gendron, 2008; Soley, 1995).

Commercialisation of university research became prominent with the passage of the 1980 Bayh-Dole Act in the USA, which gave universities the incentive to patent inventions resulting from publicly funded research (Decter et al., 2007). From the mid-1990s, many OECD nations followed the USA example by granting intellectual property ownership rights to universities to encourage research commercialisation to supplement their public research funding with private funding (OECD, 2003). This has transformed universities into hybrid organisations (Parker, 2012), often being public sector situated but expected to pursue commercial imperatives. 
The pressure for commercialisation has added a new dimension to the research management practices of many universities. The boundaries between basic and applied research are being actively contested and redefined in terms of how research advances social and economic development (Calvert, 2006) and it is claimed that individual and institutional research autonomy has deteriorated due to a more commercialised research environment and increased accountability requirements (Kayrooz et al., 2007). In this new climate, universities are confronted with a complex research and development process that requires managing the competing interests of stakeholders involved in exploring and exploiting knowledge (Hardy, 1991).

While it has been argued that organisations must excel at both exploitative and exploratory innovation in order to survive and prosper (Tushman and O'Reilly, 1996), the considerable tensions between these two activities can present a management challenge (Andriopoulos and Lewis, 2009). Exploratory or 'basic' research ${ }^{1}$ is undertaken primarily to acquire knowledge and promote learning and may be seen as an end in itself, whereas exploitation activities have commercialisation in mind. Further, individual researchers tend to be incentivised by the academic value of knowledge, while government and commercial partners are focused on the exploitation value of research (Deem, 2004; Henkel, 2005). These two faces of research have fundamentally different logics and require different management strategies and structures (Tushman and O'Reilly, 1996). Indeed, Parker (2011, p. 445) notes:

\begin{abstract}
"traditional curiosity-driven, fundamental and critical research sits in increasingly uncomfortable juxtaposition with the newer industry oriented applied research agenda...with funding driven compliance being increasingly the order of the day. Increasingly the funded, short term, applied research orientation is being absorbed and internalised by universities and their academics".
\end{abstract}

\title{
Accountability Demands
}

Research commercialisation has not only changed perceptions about the relevance and economic significance of academic research, it has increased accountability demands on universities (OECD, 2005). Many governments are now attaching greater strategic priority to research quality, emphasising a shift in research outcomes towards pathways for innovation and technology development (Henkel, 2005) and linking funding to performance-based measures (OECD, 2005; Parker, 2013). Measures of research performance are also in flux (ter Bogt and Scapens, 2012). As Gibbons et al. (1994, p. 3) note, the ascension of research that is intended to be useful to industry, government and/or society (i.e. more likely to be of commercial value) requires that measures of market competitiveness and cost effectiveness must stand alongside traditional assessments of academic rigour. At the same time, government

\footnotetext{
${ }^{1}$ The literature uses various terms such as basic, fundamental, academic, scholarly and exploratory research. The term 'basic research' is used here to represent these similar ideas.
} 
funding for basic research has declined, meaning that universities must acquire research funding through other sources (Parker, 2012; 2013).

As a result of these developments, a managerial culture has increasingly informed the reprioritised research agenda (Henkel, 2005; Parker, 2013; Pettersen and Solstad, 2007) and accountability has become a powerful force in reflecting the concerns of wider stakeholders to realise the exploitation potential of university research (Altbach, 2007). Hence, accountability demands now place high value on what can be observed and measured from research (Yamamoto, 2004).

\section{Autonomy Tensions}

Increased accountability demands around research have given rise to tensions at both organisational and individual levels, with claims that demands for accountability have diminished researchers' autonomy (Altbach, 2007; Calvert, 2006; Kayrooz et al., 2007). Others have highlighted the risk that research commercialisation and its associated measurement and management systems will damage research innovation and creativity (ter Bogt and Scapens, 2012) and jeopardise the central mission and role of the university (Lee, 1996).

It has been argued that the logic of academic research aimed at advancing knowledge is fundamentally different to, and often incompatible with, the logic of commercial research aimed at generating revenues (D'Este and Patel, 2007; Gulbrandsen and Smeby, 2005; Pettersen and Solstad, 2007). While in theory there seems to be "no necessary incompatibility between being both highly autonomous and rigorously accountable", in practice "where more accountability is required, less autonomy remains" (Berdahl, 1990, p. 171). Within a research commercialisation context, it seems that achieving a 'balance' between the professional autonomy of the researcher and appropriate accountability depends on how universities organise and manage themselves (Yamamoto, 2004). This is the focus of the study reported here.

\section{THEORETICAL PERSPECTIVE}

New institutional sociology (NIS) provides useful perspectives for understanding why and how organisations adopt strategies, structures and processes to conform to the pressures of the institutional environment (Ribeiro \& Scapens, 2006; Suddaby, 2010). Its organisational view helps the "overall outcomes of university corporatisation and commercialisation become more transparent" (Parker, 2011, p. 445).

With its roots in the work of Meyer and Rowan (1977), Zucker (1977), DiMaggio and Powell (1983), Scott (1987) and Oliver (1991), NIS has been used to theorise studies of accountability and management (e.g., Covaleski and Dirsmith, 1988; Ezzamel et al., 2007). NIS characterises the institutional environment as the manifestation of institutionalised societal beliefs, rules, myths, norms and accepted practices to which organisations must conform if they are to secure 
needed resources and legitimacy (Meyer and Rowan, 1977; Scott, 2003). It is a collective creation of powerful actors who shape how organisational interests are determined and pursued. The institutional environment exerts homogenising influences via: coercive pressure (e.g. from political and regulatory requirements); mimetic pressure (organizations copy others they perceive to be more legitimate or successful); and normative pressure (e.g. from professional networks) (DiMaggio and Powell, 1983; Scott, 2003). Identifying these pressures, and how they influence universities' research commercialisation agenda, can offer insights into the management of accountability-autonomy tensions.

At the organisational level, competing institutional demands originate from the competing logics of heterogeneous organizational fields (Thornton and Ocasio, 2008). These multiple 'institutional logics' cause practice variation as actors respond strategically to institutional pressures (Lounsbury, 2008; Oliver, 1991). Institutional logics are "socially constructed, historical pattern of material practices, assumptions, values, beliefs, and rules by which individuals produce and reproduce their material substance, organize time and space, and provide meaning to their social reality" (Thornton and Ocasio, 1999, p. 804). They provide organisational actors with shared understandings of what goals to pursue and how to pursue them (Scott, 1987) and organising principles to guide social action (Thornton and Ocasio, 2008). Conflicting institutional demands may be resolved by the progressive assimilation of challenging logics (Hoffman, 1999) or, in fragmented fields when no institutional constituent clearly dominates, conflicting demands may remain unresolved (Pache and Santos, 2010). Under such conditions organisations display varying degrees of choice, awareness, proactiveness, influence and self-interest in response to institutional pressures for change (Boxenbaum and Jonsson, 2008; Oliver, 1991). Hence, attention to institutional logics may help in understanding organisational-level responses to universities' research accountabilityautonomy tensions.

NIS theory also suggests that organisations can pursue legitimation from their institutional environment while simultaneously protecting their technical environment (Scott, 2003). For example, 'bridging strategies' involve adaptation techniques such as networks, contracting and - common in the university context - collaborations. By managing differing interests, they can change institutional logics in ways that are acceptable to all parties (Gray, 2000). The use of such bridging strategies may therefore offer a useful compromise in managing research accountability-autonomy tensions.

Alternatively, 'buffering strategies' may be used in an attempt to reduce external pressures by partially detaching or decoupling activities from external contact (Oliver, 1991; Scott, 2003). Faced with competing institutional demands, organisations may decouple their formal structure and operational structures, or symbolically adopt the structures or practices demanded by institutional referents to project a legitimate image (Boxenbaum and Jonsson, 2008; Scott, 2003). Several studies identify the use of decoupling strategies to protect organisational interests, especially regarding maintaining autonomy and maximising efficiency without the need for external intervention or public scrutiny (Boxenbaum and Jonsson, 2008; Covaleski 
and Dirsmith, 1988). Such strategies could potentially be employed to defend researcher autonomy.

Other studies point to "ambidextrous" organisational configurations, with dual strategies and structures aimed at simultaneously managing competing logics. Approaches may include 'differentiation' tactics emphasising structural ambidexterity to help maintain different competencies to address competing demands (Andriopoulos and Lewis, 2009) or 'integration' tactics emphasising contextual ambidexterity, which is the capacity of organisations to align activities to common goals while adapting to changing demands in the task environment (Andriopoulos and Lewis, 2009; Gibson and Birkinshaw, 2004). Contextual ambidexterity is achieved by creating systems that enable and encourage individuals to make their own judgements about how to allocate their time across conflicting demands (Gibson and Birkinshaw, 2004; Tushman and O'Reilly, 1996). So when confronted with conflicting institutional demands, organisations will find ways to implement logics acceptable to all key institutional constituents. Such strategies may be observable in universities' responses to the competing logics of research and commercialisation.

Recent theoretical debate has identified avenues for extending NIS. One concerns a greater appreciation of the role of agents in shaping how and why organisations respond to institutional pressures, thus explaining diverse responses within seemingly similar institutional environments (Lounsbury, 2008; Moll et al., 2006). This can offer insights into how individuals and groups interpret institutional pressures and respond to stabilise or reshape organisational structures. However, researchers using NIS have been cautioned against focusing on the agency of isolated "heroic actors" at the expense of contextualising a case study within the interplay of multiple actors and their everyday organisational work (Suddaby et al., 2010, p. 1237). Cognisant of this, we employ "a model of agency in which power is more distributed or embedded in larger social networks or structures" (Suddaby et al., 2010, p. 1237). Rather than seeking to trace the agency of individuals, we incorporate the perspectives of key sets of actors (university managers and researchers) who have the capacity to influence organisational norms, values and structures.

A further NIS extension involves "institutional work" - i.e. "the practices of individuals and collective actors aimed at creating, maintaining, and disrupting institutions" (Lawrence et al., 2011, p. 52). As Suddaby (2010, p. 15) notes, these day-to-day practices are often aimed at maintaining stability or "at least the appearance of stability" in the face of pressures for change. Also, NIS's institutional focus can be complemented with a more "micro" view of organisational processes (Moll et al., 2006, p. 188; Suddaby, 2010). For example, Ribeiro and Scapens (2006) note that organisational level analyses must also surface the conflicts and power distributions that lie within the 'black box' of the organisation. Hence, our organisational-level analysis incorporates the perspectives of university managers and researchers in order to understand how organisational strategies and structures respond to institutional pressures.

Finally, there have been calls to pay greater attention to the influences of history, context and values when using NIS. For example, Suddaby et al. (2010, p. 1238) note that organisational 
context is "shaped by prior and local institutionalized patterns that relevant stakeholders can support, change, or use to further their interests" and that values are a key determinant of organisational change processes. Similarly, Battilana and Dorado (2010) note that attention to context is important in understanding organisational responses to competing institutional logics. Such attention may help in responding to Lounsbury's (2008) call to use NIS to study organisational heterogeneity and practice variations. To highlight the effects of context, we use NIS to theorise two case organisations whose differing types, histories and values may shape their responses to identical institutional pressure towards research commercialisation.

In sum, while NIS offers an appropriate theoretical lens for our predominantly organisationallevel analysis, its recent developments also accommodate the consideration of how local, intraorganisational agency shapes responses to institutional pressures. Indeed, several prior accounting studies illustrate the use of NIS in conjunction with a consideration of the active role of individuals and groups (e.g., Ezzamel et al., 2007). Hence, the elements of NIS theory combine to provide a framework for analysing how organisational strategies may assist universities to manage accountability-autonomy tensions arising around research commercialisation.

\section{RESEARCH METHOD}

This study was carried out via case studies of two universities. This method allowed an indepth examination of accountability-autonomy tensions within the situated context of university research and commercialisation practice. It also facilitated comparisons to provide robust and reliable results (Yin, 2009).

Data for this study was derived from archival material and semi-structured interviews. The archival data comprised the two case universities' strategic documents (charters, profiles, strategic and investment plans), annual reports, newsletters and website information over eight years (2002-2012). Information was also gathered from other secondary sources such as government reports and statements of strategic research priorities, and publications relating to national, international and university-specific research issues. Accessing archival data enabled an understanding of strategies, structures, processes and actions over time, thus providing a basis for data triangulation against ex-post interviews. The 2002-2012 period captured a time when universities' research management practices were under pressure to adapt towards commercialisation and accountability-autonomy tensions became exacerbated by reduced government funding.

To understand how the tensions between researcher autonomy and accountability were perceived and managed, interviews were conducted with researchers, research institute and centre directors, commercialisation company chief executive officers and commercialisation company directors at the two universities. Interviews were also conducted with senior university staff and senior government policy and funding advisors. Their inclusion provided 
a broader understanding of universities' research management and accountability obligations. In total 28 interviews were conducted from December 2007 to June $2009^{2}$.

Each interview lasted one to one-and-a-half hours. Interviews were tape recorded, transcribed and saved as word files. Qualitative analysis software NVivo 8 was used to assist the coding process. Interview data and archival data were analysed in parallel to allow common patterns and themes to emerge, and to ensure appropriate data triangulation (Patton, 1990). Preliminary findings from the two cases were also compared to identify commonalities and divergences in their patterns and themes. The results of the data analysis are presented in the findings section, but first the research setting is outlined as context for this study.

\section{THE RESEARCH SETTING}

"Premier" and "Universal"3 are the two New Zealand universities used as case studies. Premier is one of New Zealand's largest universities in terms of student enrolments and staff employed. Established over 100 years ago, Premier has a reputation as a research-intensive university. Its strategic documents state a commitment to excellence in all aspects of research endeavours from fundamental research, to innovation and applied/developmental research, through to commercialisation of research and intellectual property (Profile 2008; Charter, 2003). Premier has been involved with research commercialisation for nearly thirty years, making it one of the earliest universities in New Zealand to engage in such activity. It established a large commercialisation company that protects and commercialises the university's intellectual property, runs its contract research activities, and supports an increasing number of commercially-focused, specialist research centres.

Universal is a fast growing, newer university that emerged from a teaching-centred culture. It describes itself as a "university for the changing world...stimulated by research that advances intellectual debate, discovery and change" (Investment Plan, 2015-2017). Over the past decade, it has undergone change aimed at strengthening its research and its strategic plans have emphasised fostering research that benefits practice and the social and economic advancement of the nation. Universal is relatively new to research commercialisation, having only engaged in these activities since the early 2000s. In recent years Universal has made a significant commitment to developing and commercialising its research and intellectual property, placing great importance on its stakeholders to influence and guide its commercialisation activities. Consistent with NIS's recognition of the importance of organisational contexts reflecting local histories, values and patterns (Lounsbury, 2008; Suddaby et al., 2010) the research commercialisation contexts of the two case study universities and their approaches to managing accountability-autonomy tensions are described next.

\footnotetext{
${ }^{2}$ Further details of the interviews and documents analysed are available from this journal's editorial office.

${ }^{3}$ Names are disguised to preserve anonymity.
} 


\section{THE PREMIER UNIVERSITY CASE}

Pressures for research and commercialisation at Premier originated from numerous sources including: the institutional demands of the global knowledge-based economy; coercive pressure via government research funding; normative demands from research professionals and industry; and the growing influence of the marketization of higher education. From an NIS perspective, these global, national and local contextual elements shaped Premier's responses and organisational processes. Thus Premier adopted a strategy:

...to undertake high quality research which contributes to social, economic, environmental and cultural development; ... to attract, encourage and retain the best possible researchers; and to provide the appropriate infrastructure and resources to support research." (Premier Strategic Plan, 2005-2012)

Premier's strategic documents identified its key research stakeholders and potential sources of institutional logics as business and industry, staff and students (the researchers), the wider community, government, and some leading international research collaborators. They also specified that Premier's accountability relationship with its stakeholders related to the advancement of research projects, the enhancement of intellectual development, gaining peer and professional recognition, and producing high quality research. Government, a key stakeholder, provided core funding and in return held Premier accountable for producing research outputs that help drive the nation's social and economic goals.

At the same time, a reduction in government research funding forced Premier to seek alternative funding to develop its research capability. Consequently, research commercialisation has become an important means of providing both the opportunity and funds to develop research capability. From an NIS perspective, Premier exhibited the beginnings of contextual ambidexterity in creating new systems to adapt to changing task environment demands. This university "is systematically seeking to identify opportunities for new, profitable, commercial activities" (CEC-P). Thus, securing alternative funding sources represents Premier's attempt to shape its own context as a means of managing the coercive pressures of government funding reductions, partly through achieving ambidexterity in developing multiple responses aimed at maintaining research funding and momentum (Andriopoulos and Lewis, 2009; Suddaby et al., 2010). In line with international trends, the move towards research commercialisation portrays Premier as a modern and innovative university. As Premier's Director of Commercialisation noted:

"... the greater the number of projects that get commercialised, your international reputation as a university grows ... that then flows into attracting other top-flight academics, then that flows into ... attracting top postgraduate students ... So, it's one after the other, you grow your reputation." (DRC-P) ${ }^{4}$

\footnotetext{
${ }^{4}$ See the Appendix for the interviewee codes.
} 
Alongside external stakeholders' increased demands have sat those of Premier's researchers who expect to enjoy considerable professional autonomy in developing an enterprising research culture necessary for commercialisation. These expectations derived from Premier's Strategic Plan 2005-2012, which advocated that staff “...conduct research in a manner which meets the needs of external parties while at the same time adhering to the principles of academic freedom and institutional autonomy". In this sense, Premier has attempted to manage multiple institutional logics introduced by different groups of external stakeholders through assimilating their requirements into its research commercialisation strategies.

Premier, like many contemporary universities, is caught between scholarly values and those represented by commercialisation. Senior managers recognised that researcher autonomy is necessary to encourage the development of research programmes. Thus, Premier became contextually ambidextrous (Gibson and Birkinshaw, 2004; Tushman and O'Reilly, 1996) by maintaining systems that allowed key organisational groups to manage opposing objectives by making their own decisions about how to allocate their research time. Premier also recognised that its fiscal survival depended on funding from research commercialisation and related financial accountability. The tension between these two value sets was managed via two major strategies: strategic planning and management structures. Here we see management attempting to create an internal organisational environment that facilitates multiple institutional logics through compromise between researchers' and management's goals.

\section{A Strategic Planning Approach}

Coercive and mimetic pressures arising from funding and accountability requirements compelled Premier to adopt strategic research goals that were aligned with government research and funding priorities. Accordingly, Premier's strategy documents noted the university's reliance on external funding (Premier Profile, 2008) with its Strategic Plan 20052012 endorsing the provisions of the Education Act 1989 sections 161(2) (b), which protects "the freedom of academic staff and students to engage in research", and 161(1), which requires "academic freedom and the autonomy of institutions to be preserved and enhanced". This reflected Premier's employment of contextual ambidexterity to alleviate autonomy tensions. In accommodating the need for external resources and legitimacy, as well as academic freedom, formal strategy documents served as bridging mechanisms that enabled the alignment of the "University's Strategic Plan consistent with the priorities of the Tertiary Education Strategy (TES) 2007-2012” (Premier Profile, 2008).

Rewards, incentives, rules and sanctions are important institutional elements that motivate or regulate organisational behaviour (Scott, 2003; Lam, 2011). Premier's researchers were primarily motivated by publications as a measure of their performance, and usually had no immediate commercialisation plans. Moving towards research commercialisation was considered contrary to their best interests as academics. Frustration was expressed that "the signals from publication-based research measures drive the university culture to a large extent and do not reward and recognise commercial outcomes" (CEC-P). At the same time, some researchers felt that funding metrics constrained researcher autonomy by channelling efforts 
into areas that attracted external funding rather than supporting long-term, experimental research. Thus the researchers, as a key actor group, felt threatened by these coercive, government-triggered pressures and experienced competing logics that produced unresolved tensions for their roles and futures (Lawrence et al., 2011; Pache and Santos, 2010).

In an attempt to manage these tensions, Premier's strategy was to "maintain an appropriate balance between 'blue skies', 'strategic', and 'applied' research, with strong links to the academic community (national and international) and 'end users' within its communities of interest" (Premier Profile, 2008). Hence, Premier's strategic plan 'buffered' the university from external pressures through a process of separation (Etzkowitz, 2003), that is, setting up research boundaries or structures to develop research groups that did not conflict with commercialisation interests. It also 'bridged' different research perspectives through a process of integrating interests and managing competing logics (Etzkowitz, 2003; Boxenbaum and Jonsson, 2008; Huxham and Hibbert, 2008), i.e. framing basic research ideals in economically and socially responsible terms to facilitate research collaboration towards commercialisation.

\section{Management Structures}

In an attempt to balance researcher autonomy with accountability demands, Premier placed strategic importance "on building high-performance research groups operating in key research areas in each of the broad disciplines undertaken by the University" (Premier Profile, 2008-2010). It established two research institutes as structurally 'ambidextrous' organisations to build research capability and develop projects for commercialisation (Andriopoulos and Lewis, 2009; Tushman and O'Reilly, 1996). Both institutes had autonomous management structures and budgets that decoupled them from Premier's academic units, and their funding was derived mainly from external sources. These institutes also served as bridging mechanisms by promoting commercialisation-supporting collaborations between researchers (Gray, 2000; Huxham and Hibbert, 2008).

In addition to its two large research institutes, Premier had eight small, multi-disciplinary research institutes and almost forty small research centres hosted by faculties and schools that provided infrastructure support. Researchers operating under these management structures had autonomy to set their research agenda, manage their projects and budgets, engage in institutional work and establish collaborations. In return, they were accountable for developing basic research to support the university's mission. The research institutes and centres enabled Premier to develop research capability through the collaborative efforts of multi-disciplinary researchers "thinking institutionally" to uphold the institution of a university and what it stands for (Helco, 2008 cited in Lawrence et al., 2011; p. 54). Not only were researchers concerned to maintain the institution via their institutional work, they acknowledged the need to re-create it as modern and responsive to commercialisation imperatives. For example, one researcher emphasised that "we can't afford just to be doing blue sky research...we can get more value by also looking at commercialisation" (RS-1). Thus, Premier had to some degree shaped its interpretive mechanisms for conditioning how its academic groups would respond to government imperatives and facilitated the development of shared institutional logics that 
assisted researchers and managers to pursue shared objectives (Suddaby et al, 2010; Thornton and Ocasio, 1999).

Premier's research institutes and centres were used as bridging mechanisms, facilitating new collaborations as well as the pursuit of commercialisation goals. While institutes and centres had autonomy, their funding was performance-based and Premier was responsible for discharging accountability consistent with the research priorities of its funders. In sum, the management structures created around research institutes and centres promoted collaboration and the development of shared institutional logics that bridged managers' and researchers' selfinterests (Gray, 2000; Reay and Hinings, 2009).

Premier also sought to manage research accountability-autonomy tensions by forming a wholly-owned, autonomous commercialisation company that was decoupled from the university structure. It was "set us up as a separate business unit so we could act as a commercial entity, and de-politicise decisions" (CEC-P). The commercial company could be seen as a further bridging mechanism, fostering collaborations between researchers (Huxham and Hibbert, 2008) and facilitating partnerships with research institutes and centres. However, it also served as an important buffering or decoupling mechanism to minimise the conflict between basic research values and the logic of commercialisation (Scott, 2003). According to Premier's CEO of Commercialisation, its outcomes were not achievable under the university structure, largely due to the influence of university politics. He noted: "I cannot emphasise this enough. It is very convenient sometimes to constrain behaviour according to other prerogatives that exist in the university" (CEC-P).

To balance autonomy with accountability, the commercial company maintained structural and contextual ambidexterity via its own governance and management structures, financial management, and intellectual property development. Despite this autonomy, the company remained accountable to Premier for the achievement of its objectives and performance measures. Also, its strategic plan was aligned with Premier's strategic goals “... so we don't actually run in a different direction to the university" (DRC-P). Still, Premier undertook annual reporting of research activities based around its negotiated strategic objectives funded by government. Thus, Premier's buffering strategies included it symbolically projecting a legitimate image to government and other funders (Boxenbaum and Jonsson, 2008).

\section{Managing Accountability-Autonomy Tensions}

The structures and strategies outlined above demonstrate Premier's awareness of the accountability-autonomy tensions around research commercialisation. The university used formal strategic plans, incorporating buffering or decoupling and bridging strategies, to manage these tensions and also established ambidextrous research institutes and centres decoupled from academic departments. These management structures protected researcher autonomy while also encouraging researchers to think institutionally to build capability and foster research commercialisation. Further, Premier established an independent company to undertake commercialisation activities, thus ensuring that basic research values did not come into conflict 
with research commercialisation goals. Bridging strategies, in the form of collaborations between institutes, centres and the commercial company, facilitated the complementarities between basic research and commercialisation. Through these mechanisms, Premier supported the development of complementary institutional logics that managed the competing pressures and agendas to which both researchers and management were exposed.

\section{THE UNIVERSAL UNIVERSITY CASE}

Like Premier, Universal faced homogenising pressure for research and commercialisation from the institutional environment. There was regulative and coercive pressure from government's research policies and funding mechanisms to develop research quality and capability to meet national social and economic development goals. There was also normative pressure from research peers and industry to create value from research and transfer knowledge for societal benefit (DiMaggio and Powell, 1983; Scott, 2003). Universal's strategic documents identified the key stakeholders to whom it was accountable for research and commercialisation (Universal Strategic Plan 2007-2011). Universal's Director of Planning noted: “...we serve a big regional population, a national population and an international community and within that there are lots of varying interests" (DRP-U).

Like Premier, in response to global, national and local institutional and accountability pressures, Universal adopted strategies to:

“...develop [its] research reputation ... capability and capacity... provide opportunities for staff to engage in research... [and] work with businesses and the professions [and] ... communities to conduct research that is relevant to the social and economic development of New Zealand and is of an international standard [and]... will provide opportunities for commercialising research."

(Universal Strategic Plan, 2007-2011)

However, tensions between researcher autonomy and accountability were apparent. Universal's General Manager and Finance Director noted: "We are a university that is very heavily dependent on government and student funding, and it would be really nice to have an alternative" (GMF-U). So Universal's strategic plans imposed accountability obligations on researchers to produce quality research that met the university's funding goals and also provided innovative solutions to industry problems. Accordingly it targeted research contributing to national social and economic development goals (Universal Investment Plan, 2008-2011). From an NIS perspective, management prioritised the externally-imposed research commercialisation logic and imposed it upon academic staff goals and research values.

However, Universal researchers noted: "....the moment people start interfering is the day that I disappear" (RPS-U).They also believed that autonomy was necessary in developing an enterprising research culture that could lead to commercialisation outcomes. As one Research Institute Director (also a researcher) noted: 
"The university is smart enough to know that a person like me will not stand for interference. If you give me the field I will run it ....... They will get high profile, they get money, they get research outputs, if they let me run it." (ID3-U)

Thus, researchers' and management's responses to external coercive pressures differed markedly, with resulting internal conflicts threatening to derail institutional performance and responsive management of government pressures (Ribeiro and Scapens, 2006; Suddaby et al., 2010). Thus, internal actors felt that management was not providing systems that would assist them to adapt to the changing task environment. That is, contextual ambidexterity was missing.

\section{Strategising Tension Management}

Initially, Universal established research commercialisation as a separate activity, with ambitious goals decoupled from basic research priorities. However, its 2005 and 2006 annual reports indicate that this decoupling strategy failed to achieve commercialisation objectives. Universal's senior management soon realised that "fundamental differences between an academic approach to things and the commercial approach" caused a "clash of culture" (CMG-U). A high profile researcher confirmed this view, admitting that many researchers are only interested in basic research since it is viewed as "...the only game that is going to reward us" (RS1-U).

To manage this tension from conflicting institutional logics (Ribeiro and Scapens, 2006; Thornton and Ocasio, 2008), Universal used its formal strategic plans as a bridging mechanism to align basic research and commercialisation goals (Reay and Hinings, 2009), in the hope that "... success in increasing research activity will result, inter alia, in a research-rich environment for learning and teaching, an improved Performance-Based Research Funding ${ }^{5}$ (PBRF) rating, increased consultancy contracts and more commercialisation of intellectual property" (Universal Strategic Plan, 2007-2011). Ultimately, the financial rewards from commercialisation were seen as providing valuable resources to support researchers' quest for reputational and career rewards (Lam, 2011).

Universal experienced considerable coercive and mimetic funding and accountability pressures to adopt research goals that aligned with government's strategic research priorities. There was also normative pressure from industry and researchers (Scott, 2003) to enhance Universal's reputation for applied research. Universal used formal strategic plans to frame the scholarly ideals of research within economically and socially responsible terms by committing to "....work with businesses and the professions we serve to assist the development of leading practice [and]... conduct research that is relevant to the social and economic development of New Zealand ..." (Universal Strategic Plan 2007-2011). These strategic priorities placed new emphasis on developing basic research capability, from which commercialisation was expected to emerge.

\footnotetext{
${ }^{5}$ New Zealand universities are subject to a government research rating and funding exercise (the "PBRF"), which emphasises the quality of publications produced.
} 
By drawing links between the goals of researchers ('strengthening the University's research culture and capability') and those of research commercialisation ('more commercialisation of intellectual property'), the strategic plan became an effective bridging mechanism to align Universal's research goals with government and industry priorities. Unlike Premier, Universal attempted to buffer external pressures by decoupling internal research activities from government research agendas (Oliver, 1991; Scott, 2003). Subsequently, it abandoned decoupling and changed its strategy towards bridging competing research and commercialisation logics by promoting an institutional logic around becoming an industrylinked, enterprising institution.

\section{A Structural Approach}

Universal relied on its management and organisational structures as mechanisms to bridge the tension between research values and commercialisation goals (Boxenbaum and Jonsson, 2008; Scott, 2003). It reviewed its management structures to ensure they supported the development of both research and commercialisation. It also established smaller research centres within schools and faculties, which grew into fourteen large research institutes. Commenting on the autonomy of the research institutes, one Institute Director remarked "it's a hell of a lot of institutes to be popping up ...everybody had the freedom to do whatever they wanted" (ID1$\mathrm{U})$.

However, interviews revealed that research institutes with external funding gave researchers far greater autonomy to manage research projects and budgets. Unlike Premier, Universal did not have highly developed research management structures, or research institutes with autonomy from academic departments. Universal's research institutes were more akin to Premier's school/department-based research centres. However, many researchers felt that the structure of Universal's research institutes still offered autonomy. One research institute, whose stated mission was "to create, develop and commercialise innovative IT products", emphasised autonomy by stating that their objective was to "conduct fundamental research and publish results in top journals...". At the same time it declared that "our mission statement is also intended to reflect strongly our desire that our research will not be ivory-towered". Thus, Universal supported the development of complementary institutional logics through structurally facilitated research practice variation aimed at preserving both agendas (Boxenbaum and Jonsson, 2008; Pache and Santos, 2010).

The research institutes also served as bridging mechanisms (Gray, 2000) between basic and applied research by providing management structures, research facilities and financial resources to promote researcher collaboration and develop areas of research excellence. For applied researchers, the institutes helped to build industry linkages that supported commercialisation and provided legitimacy to help secure funding and build the university's research profile.

Universal in 2004 established a commercial company and a research commercialisation office 
intended to facilitate intellectual property management. Initially, research commercialisation was decoupled from university research activity, but in 2008, to ease tensions arising from a clash of cultures, the commercialisation office was integrated into the central research office. However, any reduction in tension can be attributed to Universal recognising the complementarity between basic research and commercialisation, even though it achieved limited success in producing commercial outputs. Thus, both management and academic groups produced collective responses to institutional pressures via structures designed to produce shared understandings of the organisation's strategic direction (Lawrence et al, 2011; Ribeiro and Scapens, 2006). Thus, Universal attempted to adapt to its external environment while protecting its existing internal technical and processual environment.

Universal's 2006 Annual Report stated that the merger of administrative divisions supporting research and commercialisation aimed "to ensure that emphasis is not only on commercialisation, but also on the contribution of commercialisation to the support and development of research capacity at the university". This suggests that commercialisation was integrated with scholarly research so the two could become complementary. However, interviewees noted that frequent changes to reporting lines and commercialisation responsibilities created instability within research commercialisation priorities, thus returning the emphasis to research performance based on government funding goals, even though "the problem is that performance-based research funding does not necessarily value much commercialisation" (RS3-U). Summing up this situation, Universal's Finance Director expressed a pessimistic view of the immediate potential for commercial research outcomes, stating that “...one would hope something would come out of it at some point, but I can't see anything major really. I think it is quite hard to make universities commercial entities anyway; it is not their raison d'être" (GMF-U). So while Universal attempted to respond to external pressures for both research commercialisation and government funding-related performance, the latter, being closer to historical research strategies, appeared likely to dominate the organisational agenda and response (Lounsbury, 2008; Suddaby et al., 2010).

Universal's commercialisation company structure was intended to function as a bridging mechanism between basic research and commercialisation, which would “... bring the technologies out of the university, package them up, so we can take the IP... and then we take it to investors..." (CEC-U). However, this commercialisation function relied heavily on the university's management structure, policies and funding support. It also relied on highly developed research capability. Hence, until all these elements were in place, commercialisation goals posed no real threat to the scholarly values of basic research. Researchers continued to direct their efforts towards basic research goals that rewarded them via career advancement and promotion and influenced university performance ratings.

\section{Towards Tension Management}

The above findings suggest that, in attempting to manage tensions between researcher autonomy and accountability for commercialisation, Universal lost focus on its 
commercialisation goals in preference for achieving basic research goals that provided government funding. Initially, Universal decoupled scholarly research from commercialisation to manage tensions, but soon realised that although they appeared to have competing logics, these activities were complementary. To allow both activities to coexist, Universal gave priority to its basic research goals from which it expected research commercialisation to develop. While the structures it developed protected researcher autonomy and enabled the pooling of resources required to build research capacity, they unintentionally reduced commercialisation to a marginal activity whose logic and values failed to contest those of basic research.

\section{DISCUSSION}

Three dominant themes emerge from this study. First, the growing funding and accountability pressures on the two studied universities led to a homogenisation of their research goals and strategies, which in turn helped to ease accountability-autonomy tensions. Second, although both universities seemed to invoke similar managerial strategies regarding research commercialisation, the differing outcomes suggest that the effectiveness of such strategies is contextually shaped and that accountability-autonomy tensions may be easier to manage in contexts that provide highly developed research capability, structural ambidexterity, autonomy over resources, and commercialisation incentives. Third, the universities employed decoupling and bridging strategies to exploit complementarities between their basic research and commercialisation. Each of these themes is now elaborated.

\section{Institutional Environment Pressures and Homogenisation}

The organisational field of research commercialisation is increasingly shaped by pressures from the institutional environment. Coercive pressure is applied by governments via funding regimes that requires universities to comply with research performance and accountability measures. In our study, the government was not a "passive or disinterested" institutional entity, but rather was "active and engaged" in wielding power and pressuring universities towards a research commercialisation focus (Suddaby et al., 2010, p. 1237). For the two case universities, this coercive pressure compelled particular forms of homogeneity in their research conduct. To qualify for government funding, both universities were under pressure to mirror the government's research priorities and performance metrics in the strategic and investment plans that signalled what their researchers 'should' do. So, instead of becoming 'active resistors' to institutional pressures, both universities found a way to go along with the change (and remain accountable) while managing the challenges to researcher autonomy.

Conformity to shared norms, values and beliefs also regulated the conduct of researchers. In this study, normative and mimetic pressure from research peers and organisations (e.g. research institutes and centres) reinforced researchers' demands for autonomy. At the same time, these 
pressures led to a greater homogenisation of research structures and processes that helped to foster collegiality and collaboration. Mimetic and normative pressures within the international environment also promoted conformity to the growing view of research commercialisation as a 'legitimate' part of the institutional work of university researchers. The adoption of a research commercialisation mission can, therefore, be seen as an attempt by both universities to exert power via a collective agency of research networks and structures to help maintain stability as well as portray themselves as modern, innovative institutions to enhance their international research reputations.

These findings support Parker's (2011) view that institutional pressures lead to a growing homogenisation of university mission statements, strategic plans and operational priorities. Despite their different histories and profiles, Premier and Universal had similar research missions and goals, and their mimicking of government priorities helped the two universities achieve legitimacy and ongoing funding. This homogenisation, which is underpinned by shared beliefs and a common interpretation of institutional environment pressures, helped to ease researcher accountability-autonomy tensions by requiring researchers to converge towards common modes of institutional action and collaborative behaviour in order to access resources and gain legitimacy for their research.

\section{Creating Context and Ambidexterity}

Although both universities seemed to invoke similar strategies in dealing with research commercialisation, the outcomes differed. This suggests that, even though organisations operating in similar institutional environments may gravitate towards homogeneous structures and processes (Parker, 2011), the outcomes may be contextually shaped. Our two case universities' responses to institutional pressures appeared to be shaped by their different values, histories and prior structures, and partly shaped by actors responding "locally, creatively, incrementally, and more or less reflexively" (Lawrence et al., 2011, p. 57). Hence, by comparing the two cases we were able to take account of the actions and processes that resulted from the agency of organisational actors (managers and researchers) in response to institutional pressures around research commercialisation, rather than focusing only on the outcomes or on the "dramatic actions of the heroic entrepreneur" (Lawrence et al., 2011, p. 57).

Our findings also show the effect of contextual factors in shaping managerial strategies. Universal was a newer university that saw the development of research capability as its first priority. It used integration strategies with a focus on contextual ambidexterity to align research activities to its goal of capability development, from which it expected commercialisation opportunities to flow. In contrast, Premier was a long-established, large university with highly developed research capability and considerable experience of research commercialisation (Premier Annual Report, 2006). Premier established a company to advance research commercialisation, while its autonomous research institutes remained primarily focussed on scholarly research. This configuration reflected Premier's reliance on differentiation strategies, with an emphasis on structural ambidexterity - i.e., separate organisational structures for 
scholarly research and commercialisation - that protected researcher autonomy while also advancing commercialisation goals.

In sum, our findings suggest that where research capability and commercialisation capacity are highly developed, the adoption of ambidextrous organisational configurations may help to manage accountability-autonomy tensions around research commercialisation. Being ambidextrous requires autonomy of budgets, human resources, systems and structures, as well as a cultural context that allows flexibility and incentives to researchers to exercise their judgement in pursuing basic research or commercialisation (or both). On the other hand, an under-developed research capability may result in commercialisation becoming a marginal activity because the focus is still on building research rather than seeking the next step of commercialisation.

\section{Decoupling and Bridging}

This study has identified two modes of decoupling - proactive and reactive/defensive - used as adaptation techniques to manage the competing logics of commercialisation and scholarly research and ease accountability-autonomy tensions.

Premier used proactive decoupling by creating separate business processes, structures and cultural contexts to support the activities and risk-taking behaviours required for research commercialisation. Reactive decoupling was used as a defensive mechanism by Universal to give the appearance of accepting commercialisation logic in order to enhance its public image and provide legitimacy and accountability for funding. The establishment of a research commercialisation structure at Universal was largely symbolic since Universal's main priority continued to be the development of research that met government performance metrics. Researchers were incentivised to pursue basic research goals that would lead to career advancement. Parker (2011, p. 445) claims that "government research ranking metrics are also becoming increasingly powerful coercive forces ..., continually reinforced by university management control systems that have been reoriented towards revenue generation and cost minimisation". However, our findings indicate that researchers at both universities saw the government performance-based funding metrics as supporting their research agenda rather than focusing it too much on commercialisation. The two universities were strategic in their response to the pressures of the institutional funding environment (Oliver, 1991) and may have purposefully complied with funding regulations/metrics or adopted specific formal structures and procedures in order to gain legitimacy and secure resources.

Our findings suggest that research commercialisation success may depend on extracting value from basic research, while commercialisation revenues could support the development of basic research. Further, managing accountability-autonomy tensions may require a determination to realise the full potential of this complementarity. The use of bridging strategies in both studied universities facilitated adaptive responses that helped achieve this. Both universities created research institutes and centres that served as effective bridging mechanisms by integrating internal and external research knowledge and assembling resources from across organisational 
boundaries. Bridging strategies used by Premier - flexible collaboration, contracting, networks, and government and industry partnerships - helped to access diverse, novel knowledge from basic research and to develop research capability from which commercialisation outcomes could flow. By encouraging cooperation, these bridging strategies helped to identify and exploit the synergies of researcher collaboration.

These findings suggest that managing accountability-autonomy tensions does not necessarily require that choices be made between the logics of basic research and commercialisation. Universal realised it needed to develop its research capability before it could achieve commercialisation success. Hence, a bridging strategy (a merger between administrative divisions supporting research and commercialisation) was adopted to support the assimilation of commercialisation logic into the basic research logic. Other bridging strategies, such as research collaborations, were used to develop research capability from which complementary commercialisation initiatives were expected to emerge and contribute to further research development.

Strategic planning documents also proved useful in managing researcher accountabilityautonomy tensions in the studied universities. Formal strategic plans appeared to embrace commercialisation while also offering protection to researcher autonomy. Both universities decoupled from their strategic plans certain commercialisation objectives and measures that threatened to constrain researcher autonomy. However, to demonstrate a credible commitment to the commercialisation mission, formal strategic plans linked university research priorities with the government's priorities of social and economic development. Hence, while strategic plans were used as a decoupling mechanism to protect researcher autonomy, they also formed a useful bridging mechanism by appearing to conform to institutional pressures in order to enhance accountability relationships with government funding agencies.

Parker (2011, p. 448) notes that while there may be "transitory decoupling between the 'new' formal values, strategies and processes and informally persisting 'traditional' versions of these, the absorption of the corporate and commercial into university life has been comprehensive and pervasive". His argument suggests that attempts at decoupling may be failing and, as a result, researcher autonomy may be eroded. However, the findings of this study indicate that decoupling may still be an effective strategy, since the studied universities were managing to protect researcher autonomy while still going along with commercialisation imperatives.

\section{CONCLUSIONS}

As universities are increasingly required to develop and exploit opportunities for research commercialisation, tensions have developed between the autonomy of researchers and the growing accountability demands of the commercialisation mission. Yet, little is known of the strategies and practices by which universities manage these tensions. Informed by NIS perspectives, this paper has examined how two universities have responded to 
commercialisation pressures and has highlighted the complex nature of researcher autonomy and accountability relationships.

This study extends the prior use of NIS theory in this area by addressing recent calls to recognise the roles of structure, institutional work and collective agency in how organisations manage the demands of their institutional environment. Our approach responds to Suddaby et al.'s (2010) appeal to examine how organizations operate as interpretive mechanisms; filtering, decoding, and responding to broader social and institutional pressures. This has allowed us to highlight differences in strategies and outcomes that cannot be explained by examining only the broader institutional environment and to use NIS in examining organisational heterogeneity and practice variation (Lounsbury, 2008).

This study makes several contributions to the research literature in this field. It supports and extends prior research that has identified the tensions between researcher autonomy and the growing accountability demands of the commercialisation mission (Altbach, 2007; Kayrooz et al., 2007; OECD, 2005; Yamamoto, 2004) and addresses the prior lack of research into how accountability-autonomy tensions are managed. Compared to previous literature identifying a deteriorated researcher environment due to the commercialisation agenda (Altbach, 2007; Calvert, 2006; Kayrooz et al., 2007; Yamamoto, 2004), this study goes further in unpacking how two quite different universities attempted to strategically manage the commercialisation agenda and its researcher impacts. Additionally, responding to prior observations that the logics of basic and commercial research are incompatible (D'Este and Patel, 2007; Gulbrandsen and Smeby, 2005; Pettersen and Solstad, 2007), this study suggests that synergies can exist between pure research and commercialisation and can be harnessed via appropriate structures and strategies.

In response to Parker's (2011) observation that the applied research agenda is being internalised by universities, our findings suggest that this may not always be at the expense of basic research if appropriate strategies are used to reconcile the competing logics of researcher autonomy and commercialisation. Further, contrary to Parker's (2011) conclusions that government research ranking metrics are becoming increasingly powerful coercive forces and that researcher autonomy is being eroded, this study suggests that decoupling strategies can be used to protect researcher autonomy in the face of commercialisation imperatives.

In summary, this study adds to our understanding of the research management practices within universities by highlighting the complex nature of researcher autonomy and accountability relationships. It goes beyond the prior literature's identification of the existence of accountability-autonomy tensions to reveal strategies by which universities have sought to manage these tensions. Furthermore, these case studies reveal differing organisational change outcomes despite a shared institutional environment and similar managerial responses, suggesting the likely influence of organisational history, context and values. Finally, this study points to the potential role of bridging strategies such as collaboration and partnerships in helping different groups of organisational actors to see their institutional logics as shared and complementary. 
This study has drawn on case studies of New Zealand universities, so the findings must be considered in relation to its historical and institutional context and the research methods employed. It has also focussed upon an organisational level of analysis. As noted by Suddaby et al. (2010) and Lawrence et al. (2011), further insights may come from a closer examination of individual agency, whether that of institutional entrepreneurs or less heroic actors engaged in their day-to-day institutional work. In addition, future studies may usefully adopt a more micro-perspective to seek further insights into ongoing processes of institutionalisation within the management and commercialisation of university research (as per Moll et al., 2006; Ribeiro and Scapens, 2006; Suddaby, 2010).

The findings of this study raise important issues for stakeholders in university research. In particular, policies concerning research funding, management and commercialisation need to recognise the tensions and provide conditions and incentives to help manage them. Our study points to some potentially useful strategies for doing so. Policymakers may better develop research commercialisation by supporting it with corresponding resources and performance benchmarks. In dealing with commercialisation, researchers should be encouraged to recognise the complementarity of the research and commercialisation logics. Furthermore, university managers may benefit from emphasising research capability development alongside their commercialisation objectives. While the adoption of symbolic systems may enhance legitimacy, failure to implement material practices and provide the appropriate cultural context to manage conflicting relationships may place university commercialisation ambitions at risk. Finally, for society, to fully exploit the potential economic and social benefits of research being carried out in universities, commercialisable research should be encouraged alongside basic research with serious attention paid to managing the associated tensions that may arise. 


\section{REFERENCES}

Altbach, P. G. (2007), 'Peripheries and Centres: Research Universities in Developing Countries', Higher Education Management and Policy, Vol. 9, No. 2, pp. 1-24.

Andriopoulos, C. and Lewis, M. W. (2009), 'Exploitation-Exploration Tensions and Organizational Ambidexterity: Managing Paradoxes of Innovation', Organization Science, Vol. 20, No. 4, pp. 696-717.

Battilana, J. and Dorado, S. (2010), 'Building Sustainable Hybrid Organizations: The Case of Microfinance Organizations', Academy of Management Journal, Vol. 53, No. 6, pp. 1419-1440.

Berdahl, R. (1990), 'Academic Freedom, Autonomy and Accountability in British Universities', Studies in Higher Education, Vol. 15, No. 2, pp.169-180.

Boxenbaum, E. and Jonsson, S. (2008), 'Isomorphism, Diffusion and Decoupling', in R. Greenwood, C. Oliver, K. Sahlin and R. Suddaby (eds.), The SAGE Handbook of Organizational Institutionalism (SAGE Publications Ltd, London).

Calvert, J. (2006), 'What's Special about Basic Research?' Science, Technology, \& Human Values, Vol. 31, No. 2, pp. 199-220.

Covaleski, M. A. and Dirsmith, M. W. (1988), 'The Use of Budgetary Symbols in the Political Arena: An Historically Informed Field Study', Accounting, Organizations and Society, Vol. 13, No. 1, pp. 1-24.

Decter, M. et al. (2007), 'University to Business Technology Transfer - UK and USA Comparisons', Technovation, Vol. 27, No. 3, pp.145-155.

D'Este, P. and Patel, P. (2007), 'University-Industry Linkages in the UK: What are the Factors Underlying the Variety of Interactions with Industry?' Research Policy, Vol. 36, No. 9, pp. 1295-1313.

Deem, R. (2004), 'The Knowledge Worker, the Manager-Academic and the Contemporary UK University: New and Old Forms of Public Management? Financial Accountability and Management, Vol. 20, No. 2, pp. 107-128.

DiMaggio, P. J. and Powell, W. W. (1983), 'The Iron Cage Revisited: Institutional Isomorphism and Collective Rationality in Organizational Fields', American Sociological Review, Vol. 48, No. 2, pp. 147-160.

Etzkowitz, H. (2003), 'Research Groups as 'Quasi-firms': The Invention of the Entrepreneurial University', Research Policy, Vol. 32, No. 1, pp. 109-121.

Ezzamel, M., Hyndman, N., Johnsen, A., Lapsley, I. and Pallot, J. (2007), 'Experiencing Institutionalization: The Development of New Budgets in the UK Devolved Bodies', Accounting, Auditing \& Accountability Journal, Vol. 20, No. 1, pp. 11-40.

Gendron, Y. (2008), 'Constituting the Academic Performer: The Spectre of Superficiality and Stagnation in Academia', European Accounting Review, Vol. 17, No. 1, pp. 97-127

Gibbons, M. et al. (1994), The New Production of Knowledge: The Dynamics of Science and Research in Contemporary Societies, (Sage Publications, London).

Gibson, C. B. and Birkinshaw, J. (2004), 'The Antecedents, Consequences, and Mediating Role of Organizational Ambidexterity', Academy of Management Journal, Vol. 47, No. 2, pp. 209-226. 
Gray, B. (2000), 'Assessing Inter-Organizational Collaboration', in D. Faulkner and M. D. Rond (eds.), Cooperative Strategy: Economic, Business, and Organizational Issues (Oxford University Press, Oxford).

Gulbrandsen, M. and Smeby, J. C. (2005), 'Industry Funding and University Professors' Research Performance', Research Policy, Vol. 34, No. 6, pp. 932-950.

Hardy, C. (1991), 'Pluralism, Power and Collegiality in Universities', Financial Accountability and Management, Vol. 7, No. 3, pp. 127-142.

Henkel, M. (2005), 'Academic Identity and Autonomy in a Changing Policy Environment', Higher Education, Vol. 49, pp. 155-176.

Hoffman, A. J. (1999), 'Institutional Evolution and Change: Environmentalism and the U.S. Chemical Industry', Academy of Management Journal, Vol. 42, No. 4, pp.351-371.

Huxham, C. and Hibbert, P. (2008), 'Manifested Attitudes: Intricacies of Inter-Partner Learning in Collaboration', Journal of Management Studies, Vol. 45, No. 3, pp.502-529.

Kayrooz, C. et al. (eds.) (2007), Autonomy in Social Science Research: The View from UK and Australian Universities, (Elsevier, London).

Lam, A (2011), "What Motivates Academic Scientists to Engage in Research Commercialization: 'Gold', 'Ribbon' or 'Puzzle'?’ Research Policy, Vol. 40, No. 10, pp. 1354-1368.

Laperche, B. (2002), 'The Four Key Factors for Commercialising Research: The Case of a Young University in a Region in Crises', Higher Education Management and Policy, Vol. 14, No.3, pp. 149-175.

Lapsley, I. and Miller, P. (2004), 'Transforming Universities: The Uncertain, Erratic Path', Financial Accountability and Management, Vol. 20, No. 2, pp. 103-106.

Lawrence, T., Suddaby, R. and Leca, B. (2011), 'Institutional Work: Refocusing Institutional Studies of Organizations', Journal of Management Inquiry, Vol. 20, No. 1, pp. 52-58.

Lee, Y. S. (1996), 'Technology Transfer' and the Research University: A Search for the Boundaries of University-Industry Collaboration', Research Policy, Vol. 25, No. 6, pp. 843-863.

Lounsbury, M. (2008), 'Institutional Rationality and Practice Variation: New Directions in the Institutional Analysis of Practice', Accounting, Organizations and Society, Vol. 33, No. 4-5, pp. 349-361.

Meyer, J. W. and Rowan, B. (1977), 'Institutional Organizations: Formal Structures as Myth and Ceremony', American Journal of Sociology, Vol. 83, No. 2, pp. 340-363.

Moll, J., Burns, J. and Major, M. (2006), 'Institutional Theory', in Z. Hoque (ed.), Methodological Issues in Accounting Research: Theories, Methods and Issues, (Spiramus, London), pp. 183-205.

Nelles, J. and Vorley, T. (2010), 'From Policy to Practice: Engaging and Embedding the Third Mission in Contemporary Universities', International Journal of Sociology and Social Policy, Vol. 30, No.7/8, pp. 341-353.

OECD (2003), Turning Science into Business: Patenting and Licensing at Public Research Organisations (OECD Publishing, Paris).

OECD (2005), University Research Management: Developing Research in New Institutions (OECD Publishing, Paris). 
Oliver, C. (1991), 'Strategic Responses to Institutional Processes', Academy of Management Review, Vol. 16, No. 1, pp.145-179.

Pache, A.C. and Santos, F. (2010), 'When Worlds Collide: The Internal Dynamics of Organizational Responses to Conflicting Institutional Demands', Academy of Management Review, Vol. 35, No. 3, pp.455-476.

Parker, L.D. (2013), 'Contemporary University Strategising: The Financial Imperative', Financial Accountability and Management, Vol. 29, No. 1, pp.1-25.

Parker, L. (2012), 'From Privatised to Hybrid Corporatised Higher Education: A Global Financial Management Discourse', Financial Accountability and Management, Vol. 28, No. 3, pp. 247-268.

Parker, L. (2011), 'University Corporatisation: Driving Redefinition', Critical Perspectives on Accounting, Vol. 22, pp.434-450.

Parker, L.D. and Guthrie, J. (2005), 'Welcome to "the Rough and Tumble": Managing Accounting Research in a Corporatized University World', Accounting, Auditing \& Accountability Journal, Vol. 18, No. 1, pp. 5-13.

Patton, M. Q. (1990), Qualitative Evaluation and Research Methods (Sage, New York).

Pettersen, I.J. and Solstad, E. (2007), 'The Role of Accounting Information in a Reforming Area: A Study of Higher Education Institutions', Financial Accountability and Management, Vol. 23, No. 2, pp. 133-154.

Reay, T. and Hinings, C. R. (2009), 'Managing the Rivalry of Competing', Organization Studies, Vol. 30, No. 6, pp. 629-652.

Ribeiro, J. A. and Scapens, R. W. (2006), 'Institutional Theories in Management Accounting Change', Qualitative Research in Accounting \& Management, Vol. 3, No. 2, pp. 94-111.

Salmi, J. (2007), 'Autonomy from the State vs Responsiveness to Markets', Higher Education Policy Vol. 20, pp. 223-242. doi:10.1057/palgrave.hep.8300154.

Scott, W. R. (1987), 'The Adolescence of Institutional Theory', Administrative Science Quarterly, Vol. 32, No. 4, p. 493.

Scott, W. R. (2003), Organizations: Rational, Natural, and Open Systems (5th International ed.) (Pearson Education, Prentice Hall, New Jersey).

Soley, L.C. (1995), Leasing the Ivory Tower: The Corporate Takeover of Academia (South End Press, Boston).

Suddaby, R. (2010), 'Challenges for Institutional Theory', Journal of Management Inquiry, Vol. 19, No. 1, pp. 14-20.

Suddaby, R., Elsbach, K.D., Greenwood, R., Meyer, J.W. and Zilber, T.B. (2010), 'Organizations and their Institutional Environments - Bringing Meaning, Values, and Culture Back in: Introduction to the Special Research Forum", Academy of Management Journal, Vol. 53, No. 6, pp. 1234-1240.

ter Bogt, H.J. and Scapens, R.W. (2012), 'Performance Management in Universities: Effects of the Transition to More Quantitative Measurement Systems', European Accounting Review, Vol. 21, No. 3, pp. 451-497.

Thornton, P. and Ocasio, W. (2008), 'Institutional Logics', in R. Greenwood, C. Oliver, K. Sahlin and R. Suddaby (eds.), The SAGE Handbook of Organizational Institutionalism (Sage Publications Ltd, London), pp. 99-129 
Thornton, P. and Ocasio, W. (1999), 'Institutional Logics and the Historical Contingency of Power in Organizations: Executive Succession in the Higher Education Publishing Industry, 1958-1990', American Journal of Sociology, Vol. 105, No. 3, pp.801-843.

Tushman, M. L. and O'Reilly, C. A. (1996), 'Ambidextrous Organizations: Managing

Evolutionary and Revolutionary Change', California Management Review, Vol. 38, No.

4, pp.8-30.

Washburn, J. (2005), University, Inc.: The Corporate Corruption of American Higher

Education (Basic Books, New York).

Yamamoto, K. (2004), 'Corporatization of National Universities in Japan: Revolution for

Governance or Rhetoric for Downsizing? Financial Accountability and Management,

Vol. 20, No. 2, pp.153-181.

Yin, R. K. (2009), Case Study Research: Design and Methods (4th ed.) (Sage Publications Inc., Thousand Oaks, CA).

Zucker, L. (1977), 'The Role of Institutionalization in Cultural Persistence', American

Sociological Review, Vol. 42, No. 5, pp. 726-743.

\section{APPENDIX 1: ARCHIVAL SOURCES}

The following list provides the key documents analysed and the period covered. Confidential documents are not included in the list.

\begin{tabular}{|l|l|l|l|}
\hline Document Type & Period Covered & $\begin{array}{l}\text { Number of } \\
\text { Documents }\end{array}$ & Institution \\
\hline Annual Reports & $2002-2008$ & 7 & Premier \\
\hline Annual Reports & $2002-2009$ & 8 & Universal \\
\hline Strategic Plan & $2005-2012$ & 1 & Premier \\
\hline Strategic Plan & $2002-2004$ & 1 & Premier \\
\hline Strategic Plan & $2007-2011$ & 1 & Universal \\
\hline Investment Plan & $2008-2011$ & 1 & Universal \\
\hline Investment Plan & $2015-2017$ & 1 & Universal \\
\hline Profile & $2009-2010$ & 1 & Premier \\
\hline Profile & 2008 & 1 & Premier \\
\hline Summary Profile & $2008-2010$ & 1 & Premier \\
\hline Charter (Updated) & 2005 & 1 & Universal \\
\hline Charter & 2003 & 1 & Premier \\
\hline Operational Priorities & $2004-5$ & 2 & Premier \\
\hline Academic Audit Portfolio & 2006 & 1 & Universal \\
\hline Profile (Parts a, b \&c) & 2005 & 2 & Premier \\
\hline Profile (Parts a, b \&c) & $2006-2008$ & 2 & Premier \\
\hline Profile & 2007 & 1 & Premier \\
\hline Profile & $2007-2008$ & 1 & Premier \\
\hline Academic Audit Report & $2008-2012$ & 1 & Premier \\
\hline Research Newsletters & $2004-2009$ & Various & Universal \\
\hline Research Policy Manual & 2009 & 1 & Premier \\
\hline PBRF Evaluation & 2006 & 1 & Premier \\
\hline Web-pages & $2004-2010$ & Various & Universal \\
\hline Web-pages & $2004-2010$ & Various & Premier \\
\hline & & & \\
\hline
\end{tabular}




\section{APPENDIX 2: INTERVIEWS}

For the purposes of confidentiality, the following list does not contain details sufficient to identify any interviewee.

\begin{tabular}{|c|c|c|c|}
\hline Interviewee & Position & Affiliation & Date \\
\hline CEC-P & CEO, Commercialisation & Premier & 25 Sept 08 \\
\hline CEC-U & CEO and Director, Commercialisation & Universal & 16 April 08 \\
\hline CES-C & CEO, Spin-off Company & Spin-off Company & 17 Sept 08 \\
\hline DRC-P & Director, Commercialisation & Premier & 30 Sept 08 \\
\hline BMC-P & Business Manager, Commercialisation & Premier & 22 Mar 08 \\
\hline CMG-U & Commercialisation Manager & Universal & 22 Jan 08 \\
\hline DDI-P & Deputy Director, Research Institute 1 & Premier & 24 June 08 \\
\hline ID2-P & Director, Research Institute 2 & Premier & 22 July 08 \\
\hline ID1-U & Director, Research Institute 1 & Universal & 15 June 09 \\
\hline ID2-U & Director, Research Institute 2 & Universal & 28 May 09 \\
\hline ID3-U & Director Research Institute 3 & Universal & 17 Sept 08 \\
\hline IM-TEC & Investment Manager, Tertiary Institutions & $\begin{array}{l}\text { Tertiary Education } \\
\text { Commission }\end{array}$ & 11 Dec 07 \\
\hline MTP-G & Manager, Tertiary Policy & Ministry of Education & 11 Dec 07 \\
\hline MPR-G & Manager, Tertiary Performance \& Research & Ministry of Education & 11 Dec 07 \\
\hline DRF-P & Director, Finance & Premier & 7 Oct 08 \\
\hline DRP-P & Director, Planning & Premier & 7 Oct 08 \\
\hline DPL-U & Director , Policy & Universal & 29 Feb 08 \\
\hline FFM-U & Faculty Finance Manager & Universal & 19 Aug 08 \\
\hline GMF-U & General Manager \& Finance Director & Universal & 5 Aug 08 \\
\hline DRP-U & Director Planning & Universal & 1 Oct 08 \\
\hline RS1-P & Research scientist & Premier & 24 June 08 \\
\hline RS2-P & Researcher \& Professor & Premier & 22 July 08 \\
\hline RS3-P & Researcher 3 & Premier & 24 June 08 \\
\hline RS4-P & Researcher 4 & Premier & 24 June 08 \\
\hline RS1-U & Researcher \& Professor & Universal & 15 June 09 \\
\hline RS2-U & Researcher \& Professor & Universal & 28 May 09 \\
\hline RS3-U & Researcher & Universal & $10 \operatorname{Dec} 07$ \\
\hline RPS-U & Research Professor/Scientist & Universal & 17 Sept 08 \\
\hline
\end{tabular}




\section{APPENDIX: INTERVIEWEE CODES}

\begin{tabular}{|c|c|}
\hline Interviewee* & Position \\
\hline CEC-P & CEO, Commercialisation \\
\hline CEC-U & CEO and Director, Commercialisation \\
\hline CES-C & CEO, Spin-off Company \\
\hline DRC-P & Director, Commercialisation \\
\hline BMC-P & Business Manager, Commercialisation \\
\hline CMG-U & Commercialisation Manager \\
\hline DDI-P & Deputy Director, Research Institute 1 \\
\hline ID2-P & Director, Research Institute 2 \\
\hline ID1-U; ID2-U; ID3-U & Directors, Research Institutes $1,2 \& 3$ \\
\hline IM-TEC & Investment Manager, Tertiary Institutions, Tertiary Education Commission \\
\hline MTP-G & Manager, Tertiary Policy, Government Ministry of Education \\
\hline MPR-G & Manager, Tertiary Performance \& Research, Government Ministry of Education \\
\hline DRF-P & Director, Finance \\
\hline DRP-P & Director, Planning \\
\hline DPL-U & Director, Policy \\
\hline FFM-U & Faculty Finance Manager \\
\hline GMF-U & General Manager \& Finance Director \\
\hline DRP-U & Director Planning \\
\hline RS1-P & Research scientist \\
\hline RS2-P & Researcher \& Professor \\
\hline RS3-P; RS4-P & Researchers 3 and 4 \\
\hline RS1-U; RS2-U & Researchers \& Professors 1 and 2 \\
\hline RS3-U & Researcher \\
\hline RPS-U & Research Professor/Scientist \\
\hline
\end{tabular}

Note: -P and -U indicate Premier and Universal 